\title{
Chromatographic Conditions Evaluation for Phytic Acid (IP6) Determination in Rice Bran Samples by HPLC
}

\begin{abstract}
iD Cristiane Canan ${ }^{1 *}$, Fernanda Delaroza ${ }^{2}$, Daneysa Lahis Kalschne ${ }^{1}$, Marinês Paula Corso', Elza louko Ida ${ }^{3}$
${ }^{1}$ Departamento Acadêmico de Alimentos, Programa de Pós-Graduação em Tecnologia de Alimentos, Universidade Tecnológica Federal do Paraná, Avenida Brasil, Parque Independência, 4232, 85884-000, Medianeira, PR, Brazil. ${ }^{2}$ Centro de Ciências Exatas, Programa de Pós-Graduação em Química, Universidade Estadual de Londrina, Rodovia Celso Garcia Cid, Pr 445, Km 380, 86057-970, Londrina, PR, Brazil.

${ }^{3}$ Centro de Ciências Agrárias, Programa de Pós-Graduação em Ciência de Alimentos, Universidade Estadual de Londrina, Rodovia Celso Garcia Cid, Pr 445, Km 380, 86057-970, Londrina, PR, Brazil. *canan@utfpr.edu.br
\end{abstract}

Phytic acid (PA) or myo-inositol-1,2,3,4,5,6-hexakisphosphoric acid (IP6) can be hydrolyzed into inositol phosphates, such as inositol pentaphosphate (IP5), inositol tetraphosphate (IP4), inositol triphosphate (IP3) and possibly inositol di- and monophosphates (IP2 and IP1) by phytases (enzyme) during grains and seeds storage and fermentation. Chromatographic conditions of mobile phase, sample diluent, column and ionic par, for IP6 determination in defatted rice bran and purified PA from rice bran, were studied in this research. Linearity, repeatability, recovery, and limit of detection (LOD) and limit of quantification (LOQ) of the method were evaluated. The best resolution occurred with the use of both C18 columns (Shim-pack CLC-ODS and Novapak) at a $45{ }^{\circ} \mathrm{C}$ oven temperature and mobile phase A (32.50\% methanol and $1.45 \% \mathrm{TBAH})$ and sample diluent da (32.50\% methanol and $1.45 \% \mathrm{TBAH})$ and $d b(32.10 \%$ methanol and $1.20 \% \mathrm{TBAH})$. The $\mathrm{R}^{2}$ of calibration curve was 0.9988 , confirming the linearity in the PA range of 1.5 to $10 \mathrm{mg} \mathrm{mL}^{-1}(r=0.9993 ; p<0.0000)$. Intra-day repeatability presented relative standard deviations (RSD) of $3.43,2.37$ and $1.88 \%$ for 8,5 , and $3 \mathrm{mg} \mathrm{mL}^{-1}$ of PA concentrations, respectively. Inter-day intermediate precision $\mathrm{RSD}$ values were $0.93,1.38$, and $3.50 \%$ for each $\mathrm{PA}$ concentration, 8,5 , and $3 \mathrm{mg} \mathrm{mL}^{-1}$ respectively. RSD values were lower than $4 \%$ for both studies, demonstrating adequate repeatability and intermediate precision for the analytical method proposed. A 91\% IP6 recovery was obtained and the LOD and LOQ were 0.05 and $0.15 \mathrm{mg} \mathrm{mL}^{-1}$, respectively. The

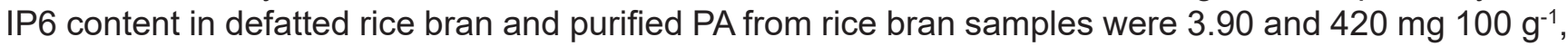
respectively.

Keywords: analytical method, high-performance liquid chromatography, inositol phosphates, myoinositol-1,2,3,4,5,6-hexkisphosphate, purified rice bran.

\section{INTRODUCTION}

Myo-inositol-1,2,3,4,5,6-hexakisphosphoric acid (IP6), also known as phytic acid (PA) [1], is a constituent commonly found in plants, and is the main storage form of inositol and phosphate in grains and plant seeds, accumulated during maturation period. PA constitutes 1 to $5 \%(\mathrm{w} / \mathrm{w})$ of most oilseeds, legumes, cereals, nuts, and pollen [2,3] representing $50-80 \%$ of total phosphorus level in seeds [4]. In

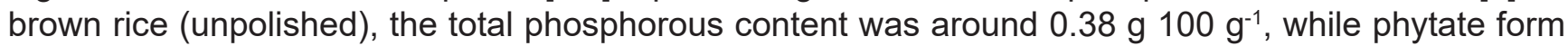

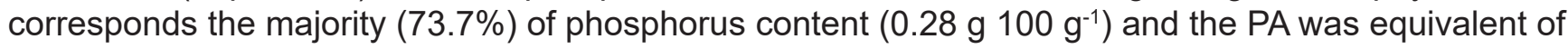

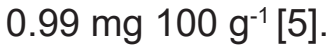

Insoluble salts are formed as a result of PA interaction with cations, named phytates [6] and chelates food micronutrients, making them non-absorbable by the intestine and thereby reducing their bioavailability $[4,7]$. However, these effects are associated with a diet poor in trace-elements and based on high PA intake [8], influenced by micronutrients linkage with other food components [9], thus, the metal ion:PA molar ratio should be considered [10]. However, PA physiological effects on health have also been studied, showing a suitable anti-oxidative effect on preventing gastrointestinal cancer [11], reducing induced-cancer in lab rats [12], potential antimicrobial effect $[13,14]$, prevention of diabetes 
[15], Parkinson's disease [16], allergens complexation [17], and heart disease [18].

The molecular mass of PA is $660.04 \mathrm{~g} \mathrm{~mol}^{-1}$ and its structure has 12 ionizable protons [19] and it has a potent chelating potential due to its unique structure (Figure 1), having a high affinity for polyvalent cations such as calcium, zinc, and iron [20]. Three of the ionisable protons are weakly acidic (pKa 5.7-7.6), three others are very weakly acid (pKa 10.0-12.0), and the remaining six ionisable protons, one from each phosphate group, are strongly acid (pKa 1.1-2.1) [21]. Thus, under physiological pH conditions phytic acid is greatly ionized, becoming negatively charged, and is able to easily react with positively charged substances [20,22]. The PA solubility depends on $\mathrm{pH}$, it being soluble at a $\mathrm{pH}<2$ [10]. Therefore, acidic solutions are widely used in its extraction, including hydrochloric acid (from 0.5 to $2.4 \mathrm{~mol} \mathrm{~L}^{-1}$ ) [23-26], acetic, sulphuric, phosphoric [27,28], and trichloroacetic acids [29].

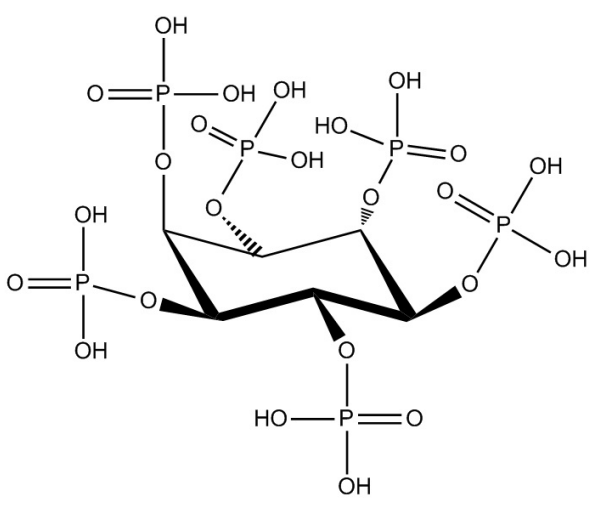

Figure 1. Phytic acid molecular structure.

Prior to PA determination, a sample preparation method of at least three steps is necessary, including the extraction, concentration and purification from vegetable sources. The rice bran PA acid direct extraction are mainly employed, and are dependent of some variables such as acid concentration, temperature, $\mathrm{pH}$, solid-liquid ratio, and extraction time [26,28]. Most used methods for IP6 extraction requires 1 to $3 \mathrm{~h}$ of extraction time with hydrochloric acid, followed by concentration and purification stages performed by ion exchange or precipitation as iron phytate [26,30].

The ion exchange chromatography method developed by Harland and Oberleas [30] is currently adopted by Association of Official Analytical Chemists (AOAC) for PA purification [31]. It is based on the hydrochloric acid extraction from the sample followed by ion exchange column purification by PA elution with $0.7 \mathrm{~mol} \mathrm{~L}^{-1}$ sodium chloride (non-linear gradient) and digestion of eluate to inorganic phosphate; the phytate content was determined colorimetrically. However, this method determination might lead to PA overestimation since it includes other non-distinguishable inositol phosphates (penta, tetra, tri, bi, and mono) $[24,32]$.

PA determination techniques in cereals were briefly reviewed, demonstrating their evolution, which began with a simple acidic insoluble ferric phytate precipitation method and progressed through instrumental methods, such as colorimetric, high performance liquid chromatography (HPLC), synchronous fluorescence spectroscopy (SFS), and isotachophoresis [33].

Among HPLC-used methods, a quantitative method with prior PA precipitation with ferric chloride followed by conversion to phytate was described [34]. Phytate was injected onto a reversed-phase C18 column and determined by atomic absorption spectrometry. It was found that PA extraction in wheat bran with $3 \%$ sulphuric acid was more efficient than the one with $3 \%$ trichloroacetic acid. In this case, PA recovery ranged from 99 to $103 \%$.

The HPLC procedures are quite sensitive and selective, and today the modern chromatographic 
systems allow rapid analysis and no longer at high costs like in the past. Additionally, HPLC procedures allow PA identification and quantification including its dephosphorylated derivatives, either by adding standards in reverse phase chromatography or by post-column reactions in ion exchange chromatography. However, several interferences were found using HPLC for IP6 and its dephosphorylated identification and determination, such as negative peaks, lack of stability in the peaks quantification, sample diluent interference with refraction index detector (RI) $[24,35,36]$. The PA determination methods by liquid chromatography coupled to mass spectrometry (LC-MS) was now available for blood and plasma. The LC-MS is now the reference method for small analyte determination, with lower LOD (30 to $80 \mathrm{ng}$ $\left.\mathrm{mL}^{-1}\right)$ and LOQ $\left(500 \mathrm{ng} \mathrm{mL}^{-1}\right)$ for PA determination [37,38]. However, the application of LC-MS is limited because is more complex and sophisticated [39].

Thus, the aim of this study was to evaluate $\mathrm{pH}$, size and column type, column temperature, methanol and tetrabutylammonium hydroxide concentration in both the mobile phase and in the sample diluent for IP6 determination by HPLC. After standardization of these variables, the linearity, repeatability, intermediate precision, limits of detection and quantification, and recovery of IP6 from rice bran were evaluated. Additionally, defatted rice brand and purified PA from rice bran were analysed in terms of IP6 content.

\section{MATERIALS AND METHODS \\ Materials, reagents, standards, and samples}

The PA was extracted and purified from rice bran obtained from rice cultivar IRGA 417 provided by the Instituto Rio Grandense do Arroz (IRGA) in the municipality of Cachoeirinha, RS, Brazil. The solvents used on mobile phase preparation were: methanol, formic acid, and sulfuric acid (Merck, Darmstat, Germany), all with chromatographic grade and ethylenediamine tetra acetic acid (EDTA) (Synth, Diadema, Brazil). The deionized water was Milli- ${ }^{\circledR}$ grade (Millipore, Billencia, USA). The mobile phases used were filtered in Millipore vacuum filtration system using $0.45 \mu \mathrm{m}$ membranes (Millipore, Billencia, USA). Myo-inositol (I5125), D-myo-inositol 1,4,5-trisphosphate hexasodium (I9766), and rice dodecasodium phytate (P0109) from Sigma (Saint Louis, USA) and 50\% (v/v) PA solution in water from Sigma-Aldrich (593648) (Saint Louis, USA), all of analytical grade, were the standards employed. The other chromatographic-graded reagents used were from different commercial brands.

\section{Sample preparation steps for IP6 determination by HPLC}

A defatted rice bran sample and a purified PA from rice bran one, were analyzed in order to determine the IP6 content by HPLC. Additionally, IP6 standard (P0109) was applied in order to optimize the chromatographic conditions. Each sample has a specific extraction process described in the sequence and all the samples were submitted to ion exchange column passage before the HPLC analysis.

Defatted rice bran: the PA from rice bran sample was extracted according to Lehrfeld [35] with some modifications. A $500 \mathrm{mg}$ sample aliquot was weighted and diluted in $10 \mathrm{~mL}$ of $0.5 \mathrm{~mol} \mathrm{~L}^{-1} \mathrm{HCl}$ and the mixture was sonicated for $5 \mathrm{~min}$, centrifuged at $25000 \mathrm{~g}$ for $20 \mathrm{~min}$ and $5.0 \mathrm{~mL}$ of supernatant was diluted to $10 \mathrm{~mL}$ with Milli- $\mathrm{Q}^{\circledR}$ water, which was then eluted in ion exchange column (described in the sequence).

Purified PA: the PA was purified from rice bran with $1.0 \mathrm{~mol} \mathrm{~L}-1 \mathrm{HCl}(1: 10 \mathrm{w} / \mathrm{v})$ at $25^{\circ} \mathrm{C}$ with $2 \mathrm{~g}$ agitation in a Bench Incubator (MA830/A, Marconi, Piracicaba, Brazil), followed by $\mathrm{pH}$ adjustment, precipitation with a $1.5 \mathrm{~mol} \mathrm{~L}^{-1} \mathrm{Na}_{2} \mathrm{CO}_{3}$ solution, filtration through qualitative filter paper Whatman \# 3 (the filtered solution was discarded), and drying for $24 \mathrm{~h}$ in an oven at $60^{\circ} \mathrm{C}$ for purification, according to method by Canan et al. [26]. The purified PA (300 mg) was diluted to $10 \mathrm{~mL}$ with Milli- $\mathrm{Q}^{\circledR}$ water and eluted in an ion exchange column.

IP6 standard (P0109): The purification process was skipped since the sample was obtained in its purified form (purity > 90\%). A $300 \mathrm{mg}$ IP6 standard aliquot was diluted with $10 \mathrm{~mL}$ Milli-Q ${ }^{\circledR}$ water and eluted in an ion exchange column. 
Ion-exchange column process: the supernatant containing the PA was eluted with anion-exchange resin to remove the inorganic phosphorous and other interfering compounds. Thus, a Dowex-AGX-4 ion-exchange column was previously prepared with $0.60 \mathrm{~g}$ resin, submitted to successive elutions with $10 \mathrm{~mL}$ Milli-Q ${ }^{\circledR}$ water, $10 \mathrm{~mL}$ of $0.7 \mathrm{~mol} \mathrm{~L}^{-1} \mathrm{NaCl}$, and $10 \mathrm{~mL}$ of Milli-Q ${ }^{\circledR}$ water [40]. Thus, each diluted 10 $\mathrm{mL}$ sample was applied to the column, eluted with $10 \mathrm{~mL}$ of $0.05 \mathrm{~mol} \mathrm{~L}^{-1} \mathrm{HCl}$ and $2 \mathrm{~mL}$ of $2.0 \mathrm{~mol} \mathrm{~L}^{-1} \mathrm{HCl}$ and collected a $2 \mathrm{~mL}$ fraction of the last eluate. For each sample prepared, $500 \mu \mathrm{L}$ eluate aliquots were transferred to $2 \mathrm{~mL}$ Eppendorf tubes and concentrated in a Speed Vac vacuum centrifuge (RC 1022, Jouan, Darmstadt, Germany) at $40^{\circ} \mathrm{C}$, until obtaining a solid residue.

In order to obtain the IP6 hydrolyzed, the last eluate collected from the Dowex-AGX-4 ion- exchange column obtained from IP6 standard (P0109) was autoclaved at $120{ }^{\circ} \mathrm{C}$ for $1 \mathrm{~h}$ and subsequently transferred to $2 \mathrm{~mL}$ Eppendorf tubes and concentrated in a Speed Vac vacuum centrifuge (RC 1022, Jouan, Darmstadt, Germany) at $40{ }^{\circ} \mathrm{C}$ until obtaining a solid residue. The residue was resuspended in Milli- ${ }^{\circledR}$ water or mobile phase and injected into HPLC.

\section{Chromatographic conditions}

Chromatographic analysis was performed using a Shimadzu liquid chromatograph (Kyoto, Japan), consisting of a LC-10AD system solvent pump, automatic injector SIL-10A with $20 \mu \mathrm{L}$ maximum capacity, a DGU-2A degassing unit, a CTO-10A oven, and a 10A refractive index detector.

A Shim-pack CLC G-ODS pre-column (1 cm x $4.0 \mathrm{~mm}$ I.D.) was used and combined with three reverse phase analytical columns: a $\mathrm{PRP}_{1}(150 \mathrm{~mm} \times 4.1 \mathrm{~mm})$ (Hamilton, Reno, NE); a Shim-pack CLC-ODS (150 mm x $4.6 \mathrm{~mm}$, I.D.) (Shimadzu, Kyoto, Japan), both with a $5 \mu \mathrm{m}$ particle size; and a C18 Novapak (150 $\mathrm{mm} \times 3.9 \mathrm{~mm}$ I.D., $\left.\mathrm{n}^{\circ} 86344\right)$ with a $4 \mu \mathrm{m}$ particles size (Waters, Milford, USA).

An isocratic elution mode, a $0.4 \mathrm{~mL} \mathrm{~min}^{-1}$ flow rate and a $20 \mu \mathrm{L}$ injected volume were utilized. Different analytical conditions were tested to find the best chromatographic conditions for separation and determination of IP6 and its inositols, as described in the following items.

\section{Organic modifier (methanol) in the mobile phase optimization}

In order to obtain the best chromatographic conditions, 27.5 and $32.5 \%$ concentration levels for organic modifier methanol were initially tested in the mobile phase. On both mobile phases, $1.45 \%$ tetrabutylammonium hydroxide (TBAH) and $0.035 \mathrm{~mol} \mathrm{~L}^{-1}$ formic acid were used. Hydrolyzed IP6 standard $\left(10 \mathrm{mg} \mathrm{mL}^{-1}\right)$ diluted in Milli- $\mathrm{Q}^{\circledR}$ water and $\mathrm{PRP}_{1}$ column were used in this step.

Sample diluent, mobile phase $\mathrm{pH}$, and column temperature optimization

After establishing the best mobile phase, the Milli- ${ }^{\circledR}$ water sample diluent and mobile phase $(32.5 \%$ methanol) sample diluent were compared. Subsequently, the mobile phase pH (from 4.0 to 4.5 ) and the column temperatures $\left(35,40\right.$, and $\left.45^{\circ} \mathrm{C}\right)$ were evaluated. PRP ${ }_{1}$ column was used for these steps.

\section{Column optimization}

For better resolution and retention time, three different columns arrangements were evaluated using the mobile phase with $32.5 \%$ methanol. The columns used alone were a PRP ${ }_{1}$ polystyrene resin used by Lehrfeld [35] and a Shim-pack CLC-ODS column. In order to increase the separation efficiency, the analytical course increased from 15 to $30 \mathrm{~cm}$, which was performed by the coupling of two columns, a C18 Shim-pack CLC-ODS and a C18 Novapak. The Shim-pack and Novapak columns were used due to the higher separation efficiency observed.

\section{Optimization of Ionic pair (tetrabutylammonium hydroxide) in the mobile phase and sample diluent}

The ionic pair (TBAH) concentration effect on the mobile phase and sample diluent was evaluated in order to improve the chromatographic profile selectivity. Lehrfeld and Morris [41] suggested that reconstituting the sample with TBAH the ghost peaks should be minimized. Thus, three mobile phases 
named $A, B$, and $C$ were tested with 3 TBAH percentage levels, $1.45,1.20$, and $0.77 \%$, respectively (Table I).

Table I. Mobile phases A, B and C employed to evaluate three percentage levels of ion pair (tetrabutylammonium hydroxide)

\begin{tabular}{lccc}
\hline Mobile phase & A & B & C \\
\hline Methanol (\%) & 32.50 & 32.10 & 30.93 \\
Formic acid 0.035 mol L$^{-1}(\%)$ & 66.05 & 66.70 & 68.30 \\
Tetrabutylammonium hydroxide (\%) & 1.45 & 1.20 & 0.77 \\
Total (\%) & 100.00 & 100.00 & 100.00 \\
\hline
\end{tabular}

Three samples diluents formed by the mobile phases (A, B, and $\mathrm{C}$ ), named $d a, d b$, and $d c$, and a fourth sample diluent $(\mathrm{X})$ with no ion pair $\left(d x\right.$, without TBAH and composed by methanol/Milli-Q ${ }^{\circledR}$ water $(1: 5, v / v /))$, were evaluated. The $d x$ was prepared and tested so that the blank (obtained by injection of mobile phase) had no positive peaks and vacancies with the mobile phase. The different sample diluents ( $d a, d b, d c$, and $d x$ ) were tested on 12 chromatography assays in duplicates (Figure 2) for each mobile phase (A, B, and C). The combination of two C18 columns (Shim-pack CLC-ODS and Novapak) and a $4 \mathrm{~mL} \mathrm{~min}^{-1}$ flow rate at $45^{\circ} \mathrm{C}$ oven temperature was used in this step.

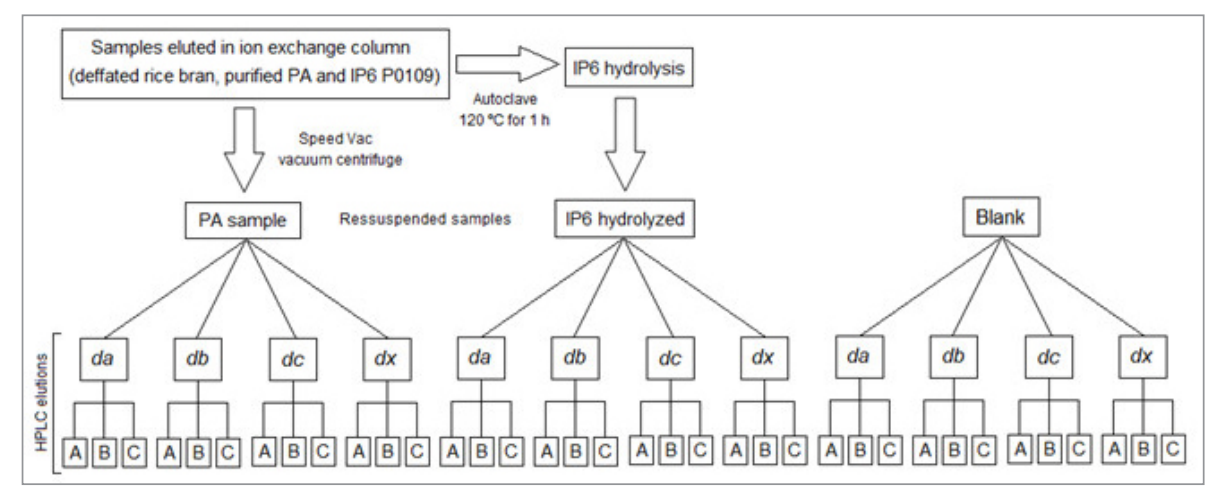

Figure 2. Samples and blank (mobile phase) elutions diagram in HPLC IP6 determination.

This assay was done in triplicate in order to evaluate the blank (mobile phase), the external standard, and the hydrolyzed sample. For blank, the interference from the mobile phase peak at the retention times of interest for inositol phosphate was evaluated; the external standard was used for IP6 quantification, and peaks selectivity was evaluated for hydrolyzed samples.

In order to examine possible mobile phases discriminations in different eluates, the scanned chromatograms were placed in the $24 \times 1750$ matrix (three mobile phases, each one tested with 4 sample diluents including the analyte in duplicate). The data were submitted to $Q$ type PCA, loadings, and hierarchical analysis $(\mathrm{AH})$.

\section{Separation factor in chromatographic profiles optimization}

This optimization was performed in order to verify the chromatographic separation of IP3, IP4 and IP5 inositols from the hydrolyzed IP6 standard. The mobile phase and sample diluent selection was based on the separation factor. Numerical representation of chromatogram quality was laborious due to the 
absence of absolute standards (IP2 and IP4), which could be used to measure the peaks resolution and separation factor. Therefore, for each chromatogram the various values for separation factor between adjacent peaks were reduced to a single number by the chromatographic response function (CRF), defined by Equation 1 [42].

$$
\mathrm{CRF}=\mathrm{h} \sum_{\mathrm{i}=1}^{\mathrm{k}}\left(\mathrm{P}_{\mathrm{i}}\right) \quad \text { Equation } 1
$$

where: CRF is chromatographic response function; $\mathrm{Pi}$ is the separation measure between adjacent peaks in a chromatogram for $k$ peak pairs, where $k$ is less than the peaks total number.

\section{Figures of merits}

The method evaluation was performed according to AOAC guidelines [31], including linearity, repeatability, intermediate precision, recovery, and LOD and LOQ estimative.

Linearity: It was determined by analysis in triplicate of standard mixtures at six different concentrations ranging from 1.5 to $10.0 \mathrm{mg} \mathrm{mL}^{-1}$, by constructing the external calibration curve and by calculating the coefficient of determination $\left(R^{2}\right)$ and significance level $(p)$.

Repeatability and intermediate precision: Five different extractions from the same sample, subject to the same extraction and analysis conditions, were analyzed using the same equipment, in short time frame. Intra-day repeatability was also studied; the extraction of the same sample was evaluated with five replicates during the day. Additionally, an inter-day repeatability (intermediate precision) was performed by analyzing a standard mixture of compounds $\left(5 \mathrm{mg} \mathrm{mL}^{-1}\right)$, which was prepared and injected at $24 \mathrm{~h}$ intervals for 5 days. The repeatability and intermediate precision results were expressed in terms of relative standard deviation (RSD).

Recovery (accuracy): It was determined by adding the test substance standard to the purified PA sample prior to analysis. Firstly, the IP6 content in the purified PA was estimated, obtaining a content of $39 \mathrm{mg} 100 \mathrm{~g} \mathrm{~g}^{-1}$. The analysis was repeated by adding the PA standard amount corresponding to $50 \%$ of the purified PA initial concentration. The analyses were performed in triplicate.

Limit of detection (LOD) and limit of quantification (LOQ): was estimated by the ratio between the standard deviation (SD) of the calibration curve and its slope, using the suggested multiplier factor by the ICH norm [43] (Equation 2 and 3, respectively).

$$
\begin{array}{ll}
\mathrm{LOD}=3.33 \mathrm{SD} / \mathrm{b} & \text { Equation } 2 \\
\mathrm{LOQ}=10 \mathrm{SD} / \mathrm{b} & \text { Equation } 3
\end{array}
$$

where: LOD is limit of detection, LOQ is limit of quantification, SD is calibration curve standard deviation and $b$ is calibration curve angular coefficient.

\section{IP6 quantification and statistical analysis}

IP6 quantification was performed by external standardization. The calibration curves were constructed considering that the chromatographic peak was proportional to the injected standard concentrations. IP6 content in defatted rice bran determined by HPLC (proposed method) was compared with the content determined by a colorimetric method [44].

Computer software Arthur, modified for microcomputers [45], was used for preprocessing calculations and Principal Component Analysis (PCA). Statistica 6.0 and Origin 7 programs were used on graphic plotting. CRF calculations were performed by AutoCad 2009. 


\section{RESULTS AND DISCUSSION}

For IP6 determination, the variation of chromatographic conditions showed important changes in the profile of chromatograms, as described in detail for each evaluated parameter.

\section{Organic modifier (methanol) as mobile phase and sample diluent}

The mobile phase with $32.5 \%$ methanol showed a chromatographic profile with better resolution of the peaks related (Figure 3b). Two peaks were detected in retention times of 7.33 and 8.41 min (Figure $3 b)$, while for the mobile phase with $27.5 \%$ methanol only one peak (10.09 min retention time) and a negative one (8.56 min retention time) were detected (Figure 3a).

The occurrence of negative peaks in PA chromatograms is not desirable, specially the adversely affect the separation and quantification of inositol phosphates. However, some other similar studies have reported the occurrence of negative peaks [24,35,36]. According to Hamada et al. [36], the TBAH increase in mobile phase (from 0.6 to $1.0 \%$ ) reduce the negative peaks and improve the peak resolution.

Ultra-pure water and mobile phase have been used as sample diluent for HPLC analysis $[46,47]$. However, in the proposed method, the mobile phase with $32.5 \%$ methanol used as sample diluent presented a better chromatographic profile, obtaining a new profile with two peaks (3.27 and 6.24 min retention times) and a vacancy between them (Figure 3c).

\section{Mobile phase $\mathrm{pH}$ and column temperature}

There were no changes in the chromatographic profiles in the 4.0 to $4.5 \mathrm{pH}$ range, hence, $\mathrm{pH} 4.3$ was selected. According to previous studies, a loss in chromatogram resolution would occur should the mobile phase $\mathrm{pH}$ increase from 4.3 to 5.2, reducing the number of peaks from 4 to 2 [35]. For column temperature, the optimal condition was observed at $45^{\circ} \mathrm{C}$. This temperature reduced the pressure column and this result is in agreement with previous studies [48].

\section{Columns}

The PRP ${ }_{1}$ column replacement by the Shim-pack CLC-ODS column eliminated the vacancy between the peaks of interest, resulting in 4 peaks in the retention times of 5.70, 6.45, 7.11 and 1.35 min (Figure $3 d)$. The use of a longer length applying two combined C18 columns, a Shim-pack CLC-ODS, and a Novapak, proved an interesting alternative to IP6 determination.

\section{lonic pair (tetrabutylammonium hydroxide) in the mobile phase and sample diluent}

Evaluating only the blank (reading the sample diluent in the mobile phase), interfering peaks were observed in the sample diluents carrying the ion exchanger ( $d a, d b$, and $d c)$. The $d b$ and $d c$ sample diluents behaved similarly in mobile phases $A$ and $B$, with a blank detected at 7.1 min. A peak delay was noticed in sample diluent $d a$, which presented the greatest ionic pair strength in the three mobile phases used (A, B, and $C$ ) with 11.5, 11.7, and $12.7 \mathrm{~min}$, respectively. The chromatographic profile for mobile phase $C$ with $d b$ and $d c$ diluents was limited to 5.7 min for IP2, IP3, IP4, IP5 and IP6 inositol readings, with the blank detected at 7.1 and $12.8 \mathrm{~min}$. No peak of interference for sample diluent $d x$ occurred at the time of interest. Figure 4 shows the three mobile phases $(A, B$, and $C)$ variation with the IP6 standard elution in $d a, d b, d c$, and $d x$. 

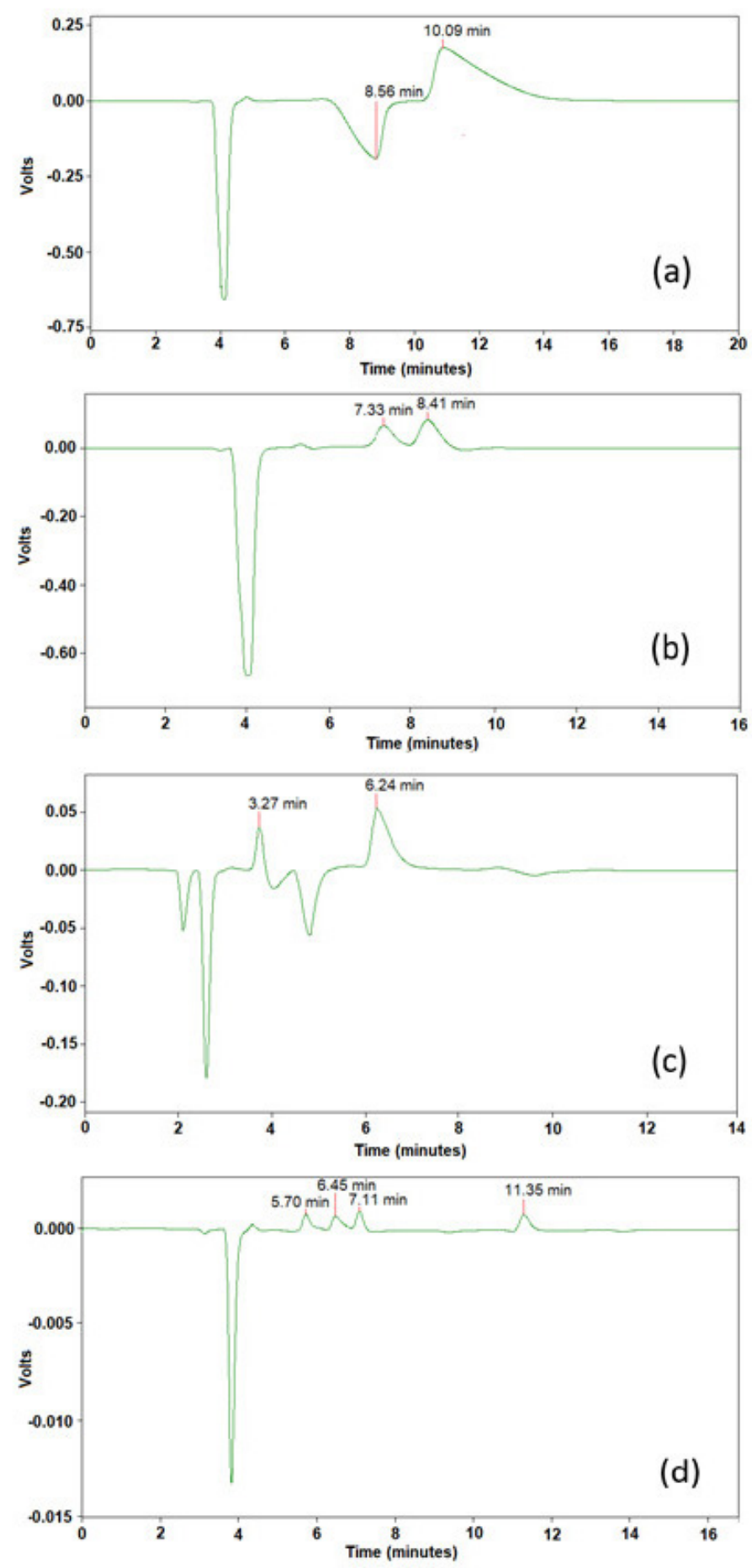

Figure 3. (a) Hydrolyzed IP6 standard eluted in the mobile phase with $27.5 \%$ methanol and Milli- $\mathrm{Q}^{\circledR}$ water as sample diluent and $\mathrm{PRP}_{1}$ column; (b) hydrolyzed IP6 standard eluted in mobile phase $\mathrm{A}\left(32.5 \%\right.$ methanol), diluted with Milli- ${ }^{\circledR}$ water and $\mathrm{PRP}_{1}$ column; (c) hydrolyzed IP6 standard eluted in mobile phase A (32.5\% methanol), diluted with mobile phase A and $\mathrm{PRP}_{1}$ column; (d) hydrolyzed IP6 standard eluted in mobile phase A (32.5\% methanol), diluted with mobile phase A and a C18 Shim-pack CLC-ODS column. 


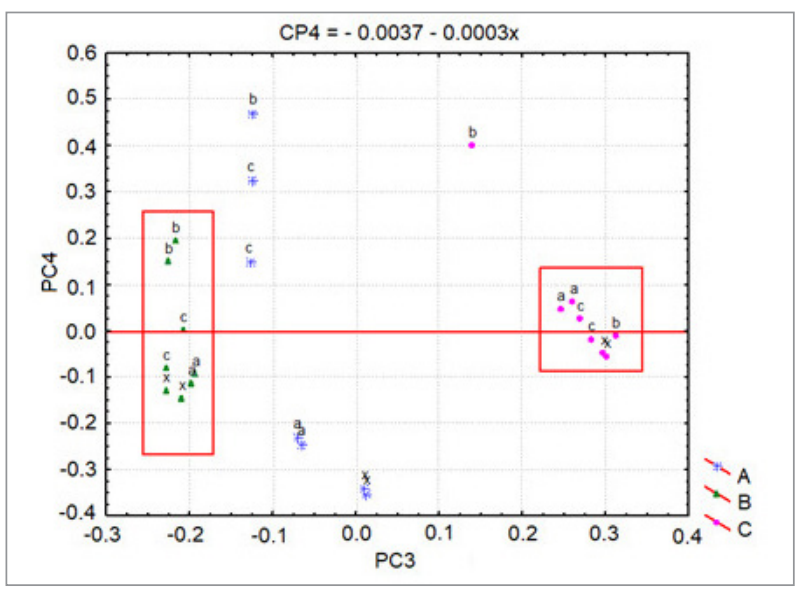

Figure 4. PCA plot (PC3 $\times$ PC4) for the sample diluents a (da), b $(d b), c(d c)$, and $x(d x)$ eluted in mobile phases $A, B, C$, and $X$.

The PCA required 10 principal components (PC) in order to explain $99 \%$ of the total data variance. Figure 4 shows PC3 x PC4 plot, which represents $5.96 \%$ of total variance. It is possible to notice, in the loading plot in Figure 5, the formation of three groups that distinguished the three mobile phases $(A, B$, and C).

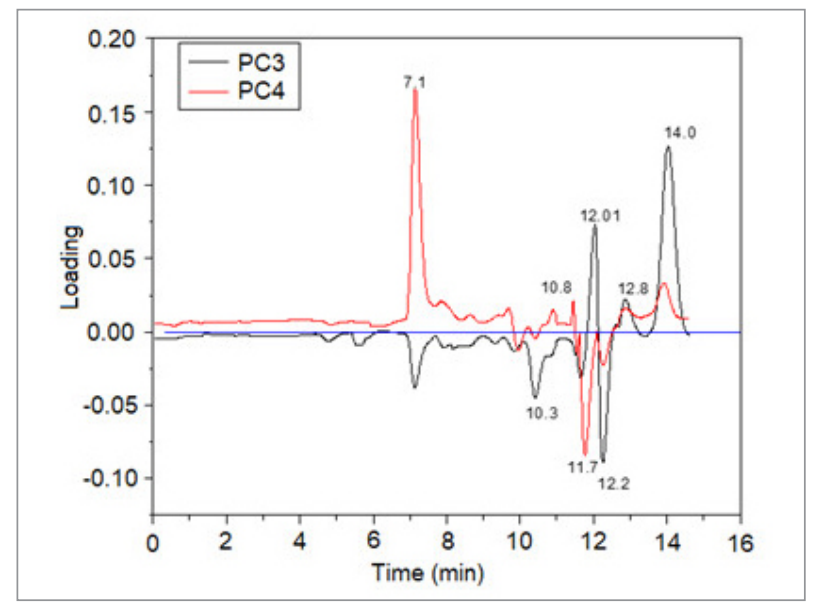

Figure 5. Loading plot (PC3 $\times$ PC4) for sample diluents $a(d a), b$ $(d b), c(d c)$, and $x(d x)$ eluted in mobile phases $A, B, C$, and $X$.

The samples eluted in the mobile phase $C$ differed from the other samples (eluted in $A$ and $B$ ) by the positive PC3, which presented the highest impact at 14 and $12 \mathrm{~min}$ retention times. Mobile phase $\mathrm{C}$ chromatograms showed the worst selectivity, with peaks IP3 and IP4 coeluted. Mobile phase A showed the greatest discrepancy between the strength of sample diluent, separated by the PC4. As previously discussed, the blank peak was detected at $7.1 \mathrm{~min}$ in $d b$ and $d c$ sample diluents and at $11.5 \mathrm{~min}$ in da sample diluent, obtaining an optimal discrimination for this phase. However, the great interest for inositol detection are the peaks after $7.1 \mathrm{~min}, 10.8,10.3,12.01,12.2$, and $11.7 \mathrm{~min}$ for instance, and some peaks of lower responses not shown in Figure 5 , in mobile phases A and B with the $d b$ and $d c$ sample diluents since they are peaks without organic solvent interferers. By the dendogram analysis (Figure 6), the distinction of the three groups at the 0.9 distance confirms the previously discussed analysis. 


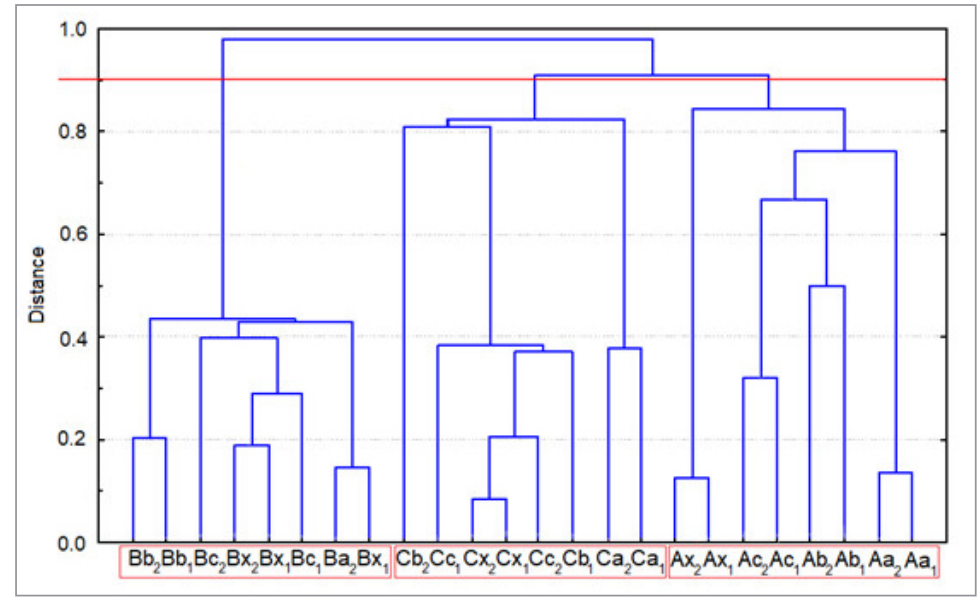

Figure 6. Dendrogram based on data from sample diluents a (da), $\mathrm{b}(d b), \mathrm{c}(d c)$, and $\mathrm{x}(d x)$ eluted in mobile phases $\mathrm{A}, \mathrm{B}$, and $\mathrm{C}$.

Thus, the mobile phase and the sample diluent choice by the chromatographic profiles quality evaluation using the CRF, showed $d a$ and $d b$ sample diluents and mobile phase $A$ as the best conditions in this study (Figure 7). Therefore, the mobile phase $\mathrm{A}$ and $d b$ were the chromatographic conditions used for the continuity in the inositol quantification.

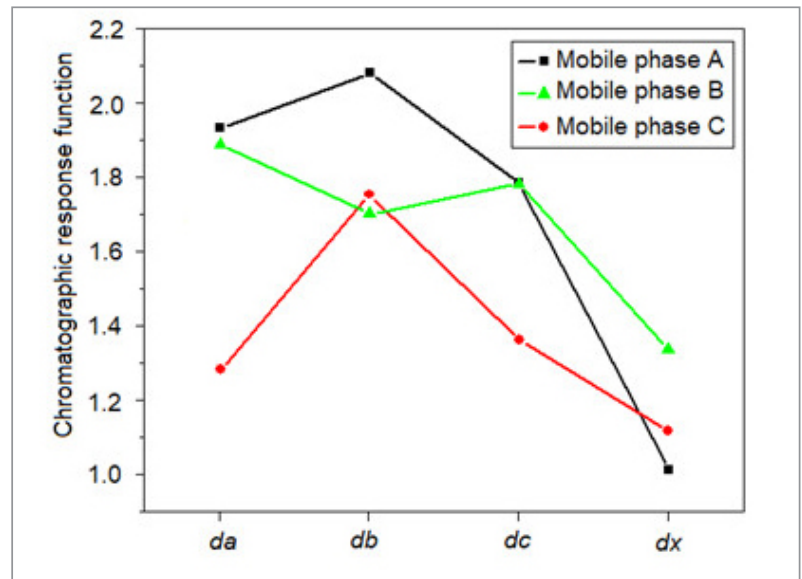

Figure 7. Chromatographic response function study in mobile phases $\mathrm{A}, \mathrm{B}$, and $\mathrm{C}$ and $d a, d b, d c$, and $d x$ sample diluents.

\section{Method evaluation}

The myo-inositol standard peak was identified at $7.0 \mathrm{~min}$, the IP3 standard peak at $6.7 \mathrm{~min}$, and the IP6 standard peak at 9.8 min in chromatograms. Similarly, Frontela et al. [47] employed the same method proposed by Lehrfeld [35] for PA determination in infant cereals, and the retention time of PA was 9.2 min in a reverse-phase C18 column.

The method was shown to be linear $(r=0.9993 ; p<0.0000)$ over the range 1.5 to $10.0 \mathrm{mg} \mathrm{mL}^{-1}$ for $\mathrm{PA}$. The calibration curve demonstrated in Figure 8 had a $\mathrm{R}^{2}=0.9988$. 


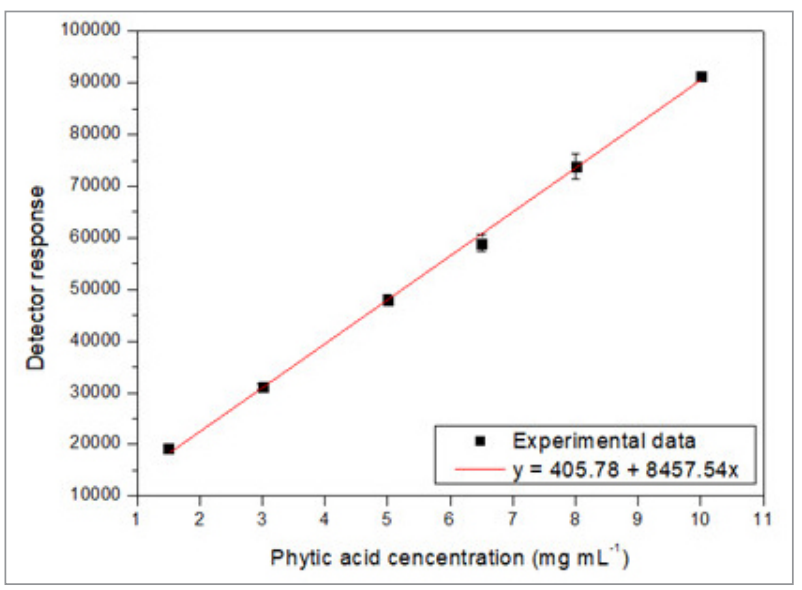

Figure 8. Calibration curve for IP6 determination (1.5 to $10.0 \mathrm{mg} \mathrm{mL}^{-1}$ range) $\left(\mathrm{R}^{2}=0.9988\right)$.

The intra-day repeatability presented RSD values of $3.43,2.37$, and $1.88 \%$ for the 5 replicates of each concentration, 8,5 , and $3 \mathrm{mg} \mathrm{mL}^{-1}$ respectively. Inter-day intermediate precision RSD values were 0.93 , 1.38, and $3.50 \%$ for each PA concentration $-8,5$, and $3 \mathrm{mg} \mathrm{mL}^{-1}$, respectively - evaluated for 5 different days. RSD values were lower than $4 \%$ on both intra and inter-day studies, demonstrating adequate repeatability and intermediate precision for the analytical method of PA quantification proposed.

A 91\% IP6 recovery was obtained. The recovery obtained was lower compared with the range of 99 to $103 \%$ reported for a quantitative method by atomic absorption spectrometry in wheat bran; in this case the sample preparation method was performed by PA extraction with sulphuric acid, precipitation with ferric chloride followed by conversion to phytate [34]. In contrast, the recovery of $90 \%$ was reported by Frontela et al. [47] employing HPLC PA determination method proposed by Lehrfeld [35].

The LOD of proposed method was 0.05 and the LOQ was $0.15 \mathrm{mg} \mathrm{mL}^{-1}$. Similarly, a LOD of $0.04 \mathrm{mg}$ $\mathrm{mL}^{-1}$ was reported [47] for HPLC PA determination using the method proposed by Lehrfeld [35].

\section{IP6 quantification in defatted rice bran and purified PA samples}

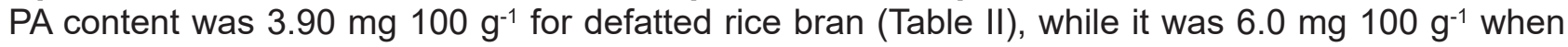
determined by a colorimetric method [44] (IP6 overestimation of 35\%), suggesting that other inositols were quantified together with IP6. Similarly, an overestimation of $27 \%$ in the PA content of infant foods were reported by the comparison of HPLC and colorimetric method [24]. The determination of PA based on the phosphorus content - as performed in colorimetric method - overestimate the real PA content because processed foods often contain partially phosphorylated inositols formed by hydrolysis of PA [41]. Additionally, the PA content in defatted rice bran (3.90 mg $\left.100 \mathrm{~g}^{-1}\right)$ was slightly higher than the PA

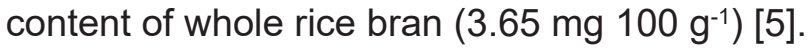

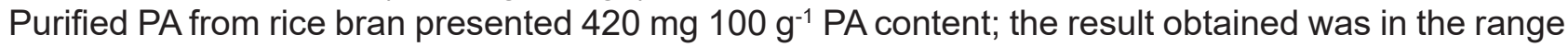
of PA content in purified PA from rice bran (335 to $708 \mathrm{mg} 100 \mathrm{~g} \mathrm{~g}^{-1}$ ) described by Canan et al. [26]. The purification step of the rice bran guaranteed around four times higher PA content compared to rice infant cereal and rice flour (Table II). It was not possible to quantify other inositols. 
Table II. PA content comparison with literature data

\begin{tabular}{lcccc}
\hline Sample & Method & $\begin{array}{c}\text { IP6 content } \\
\left(\mathbf{m g ~ 1 0 0 ~} \mathbf{~ g}^{-1}\right)\end{array}$ & $\begin{array}{c}\text { LOD } \\
\left(\mathbf{m g ~ m L}^{-1}\right)\end{array}$ & $\begin{array}{c}\text { LOQ } \\
\left(\mathbf{m g ~ m}^{-1}\right)\end{array}$ \\
\hline Defatted rice bran & HPLC & 3.90 & 0.05 & 0.15 \\
Defatted rice bran & Colorimetric & 6.0 & & \\
Purified PA from rice bran & HPLC & 420 & 0.05 & 0.15 \\
Purified PA from rice bran [26] & Colorimetric & $335-708$ & \\
Rice bran [5] & Colorimetric & 3.65 & \\
Rice infant cereal [47] & HPLC & 107.3 & 0.04 \\
Rice flour [49] & Colorimetric & 75.14 & & \\
\hline
\end{tabular}

\section{CONCLUSIONS}

A series of complex equilibrium are linked to ion pair chromatography, in this case, a good organic modifier/sample diluent/column interaction evaluation was crucial for developing this study. The evaluation using modifier methanol varying $5 \%$ resulted in a chromatographic profile improvement, as well as PRP 1 column replacement by combined C18 columns, a Shim-pack CLC-ODS, and a Novapak, increasing the analytical course. The mobile phase (A, B, and C) and sample diluent ( $d a, d b$, and $d c)$, with a $1.57 \%$ ion exchanger variation (mobile phase $A$ to mobile phase $\mathrm{C}$ ), had a negligible difference in the chromatographic profiles. Thus, the difference in the profiles was not only between the mobile phases, showing the ionic pair percentage relevance eluted with the sample.

Among the profiles studied, a loss of up to 2 peaks in the chromatographic profiles occurred. CRF showed differences in profile selectivity, where the maximum reached was at 2.08 (mobile phase $A$ and $d b$ ) and the minimum was at 1.01 (mobile phase $\mathrm{C}$ and $d a$ ). Mobile phase $\mathrm{A}$ and the $d a$ and $d b$ sample diluents provided the best responses in the chromatographic profiles.

IP6 calibration curve $\mathrm{R}^{2}$ was 0.9988 and intra-day and inter-day studies showed RSD values lower than $4 \%$ in all cases, showing adequate repeatability and intermediate precision for the analytical method proposed. A 91\% IP6 recovery was achieved and the LOD and LOQ were 0.05 and $0.15 \mathrm{mg}$

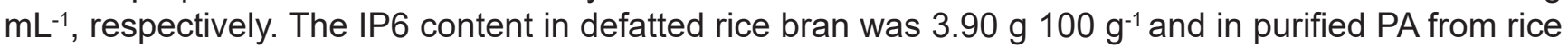

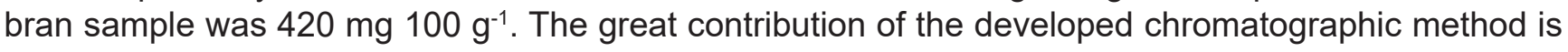
the PA overestimation solution.

Manuscript submitted: Oct. 19, 2018; revised manuscript submitted: Jan. 1, 2019; manuscript accepted: Feb. 7, 2019; published online: June 11, 2019.

\section{REFERENCES}

1. Kumar, V.; Sinha, A. K.; Makkar, H. P. S.; Becker, K. Food Chem., 2010, 120, pp 945-959.

2. Graf, E.; Eaton, J. W. Free Radic Biol Med., 1990, 8, pp 61-69.

3. Duong, Q. H.; Clark, K. D.; Lapsley, K. G.; Pegg, R. B. J Food Compos Anal., 2017, 59, pp 74-82.

4. Thavarajah, D.; Thavarajah, P.; See, C. T.; Vandenberg, A. Food Chem., 2010, 122, pp 254-259.

5. Ravindran, V.; Ravindran, G.; Sivalogan, S. Food Chem., 1994, 50 (2), pp 133-136.

6. Hurrell, R. F. Int J Vitam Nutr Res., 2004, 74, pp 445-452.

7. Bhagyawant, S. S.; Bhadkaria, A.; Gupta, N.; Nidhi, S. J Food Biochem., 2018 (DOI: http://dx.doi.org/10.1111/jfbc.12678).

8. Vucenik, I.; Shamsuddin, A. M. Nutr Cancer., 2006, 55, pp 201-209.

9. Lopez, H. W.; Leenhardt, F.; Coudray, C.; Remesy, C. J. Food Sci. Technol., 2002, 37, pp 727-739. 
10. Champagne, E. T.; Hinojosa, O. J Inorg Biochem., 1987, 30, pp 15-33.

11. Law, B. M. H.; Waye, M. M. Y.; So, W. K. W. Int J Mol Sci., 2017, 18, pp 1-20.

12. Norazalina, S.; Norhaizan, M. E.; Hairuszah, I.; Norashareena, M. S. Exp Toxicol Pathol., 2010, 62, pp 259-268.

13. Canan, C.; Bloot, A. P. M.; Baraldi, I. J.; Colla, E.; Feltrin, V. P.; Corso, M. P.; Habu, S.; Nogues, D. R. N.; Kalschne, D. L.; Silva-Buzanello, R. A. Composição antimicrobiana a base de fitato, e seu uso. BR 102018006228 0, March 27, 2018, UTFPR, Medianeira, PR, BR.

14. Kim, N. H.; Rhee, M. S. Int J Food Microbiol., 2016, 227, pp 17-21.

15. Kim, S. M.; Rico, C. W.; Lee, S. C.; Kang, M. Y. J Clin Biochem Nutr., 2010, 47, pp 12-17.

16. Xu, Q.; Kanthasamy, A. G.; Reddy, M. B. Toxicology, 2008, 245, pp 1-2.

17. Chung, S. Y.; Champagne, E. T. J Agric Food Chem., 2007, 55, pp 9054-9058.

18. Obata, T.; Nakashima, M. Eur J Pharmacol., 2016, 774, pp 20-24.

19. Costello, A. J.; Glonek, T.; Myers, T. C. Carbohydr Res., 1976, 46, pp 159-171.

20. Nolan K. B.; Duffin, P. A. J. Nutr., 1984, 114 (7), pp 1192-1198.

21. Fuh, W. S.; Chiang, B. H. J. Sci. Food Agric., 2001, 81 (15), pp 1419-1425.

22. Persson, H.; Turk, M.; Nyman, M.; Sandberg, A. S. J Agric Food Chem., 1999, 46, pp 3194-3200.

23. Blaabjerg, K.; Hansen-Møller, J.; Poulsen, H. D. J. Chromatogr. B, 2010, 878 (3-4), pp 347-354.

24. Park, H. R.; Ahn, H. J.; Kim, S. H.; Lee, C. H.; Byun, M. V.; Lee, G. W. Food Control, 2006, 17 (9), pp 727-732.

25. Phillippy, B. Q.; Wyatt, C. J. J. Food Sci., 2001, 66 (4), pp 535-539.

26. Canan, C.; Cruz, F. T. L.; Delaroza, F.; Casagrande, R.; Sarmento, C. M. P.; Shimokomaki, M.; Ida, E. I. J Food Compos Anal., 2011, 24, pp 1057-1063.

27. Han, Y. W. J. Agric. Food Chem., 1988, 36 (6), pp 1181-1183.

28. Sha, R.; Wu, D.; Wang, W.; Wang, S.; Cai, C.; Mao, J. Waste Biomass Valor., 2017 (DOI: 10.1007/s12649-017-0092)

29. Pande, R.; Mishra, H. N. Food Chem., 2015, 172, pp 880-884.

30. Harland, B. F.; Oberleas D. Journal-Association off Anal Chem., 1986, 69, pp 667-670.

31. AOAC. American Organization of Analytical Chemists. Official Methods of Analysis of the Association of Official Analytical Chemists. AOAC, Arlington, 2005.

32. Harland, B. F.; Oberleas, D. World Rev. Nutr. Diet., 1987, 52, pp 235-259.

33. Wu, P.; Tian, J. C.; Walker, C. E.; Wang, F. C. Int J Food Sci Technol., 2009, 44, pp 1671-1676.

34. Camire, A. L.; Clydesdale, F. M. J Food Sci., 1982, 47, pp 575-578.

35. Lehrfeld, J. Cereal Chem., 1989, 66, pp 510-515.

36. Hamada, J. S. J. Chromatogr. A, 2002, 944 (1-2), pp 241-248.

37. Tur, F.; Tur, E.; Lentheric, I.; Mendoza, P.; Encabo, M.; Isern, B.; Grases, F.; Maraschiello, G. J. Chromatogr. B, 2013, 928, pp 146-154.

38. Rougemont, B.; Fonbonne, C.; Lemoine, J.; Bourgeaux, V.; Salvador, A. J. Liq. Chromatogr. Relat. Technol., 2009, 39 (8), pp 408-414.

39. Lanças, F. M. Sci. Chromatogr., 2009, 5 (1), pp 27-46.

40. Ellis, R.; Morris, E. R. Cereal Chem., 1986, 63, pp 58-59.

41. Lehrfeld, J.; Morris, E, R. J Agric Food Chem., 1992, 40 (11), pp 2208-2210.

42. Glajch, J. L.; Kirkland, J. J.; Squire, K. M.; Minor, J. M. J Chromatogr A., 1980, 199, pp 57-79.

43. ICH. Q2B Validation of Analytical Procedures: Methodology. ICH, London, 1996.

44. Latta, M.; Eskin, M. J Agric Food Chem., 1980, 28, pp 1313-1315.

45. Scarminio, I. S.; Bruns, R. E. TrAC - Trends Anal Chem., 1989, 8, pp 326-327.

46. Nappi, G. U.; Ribeiro-Cunha, M. R.; Coelho, J. V.; Jokl, L. Ciência e Tecnol Aliment., 2006, 26, pp 811-820.

47. Frontela, C.; García-Alonso, F. J.; Ros, G.; Martínez, C. J Food Compos Anal., 2008, 21, pp 343-350.

48. Burbano, C.; Muzquiz, M.; Osagie, A.; Ayet, G.; Cuadrado, C. Food Chem., 1995, 52, pp 321-325.

49. Norhaizan, M. E.; Nor Faizadatul Ain, A. W. Mal J Nutri, 2009, 15 (2), pp 213-222. 